\title{
INTERNATIONAL ASSOCIATION OF
}

\section{LAW LIBRARIES}

\section{Membership Application}

International Association of Law Libraries

P.O. Box 5709

Washington, D.C. 20016-1309

U.S.A.

Nameof Applicant

Name of Institution

Address

Please check one: Personal Membership (\$55)

Institutional Membership (\$80)

Sustaining Membership (\$250)

Make check payable to the International Association of Law Libraries and send it with the application to the above address. 


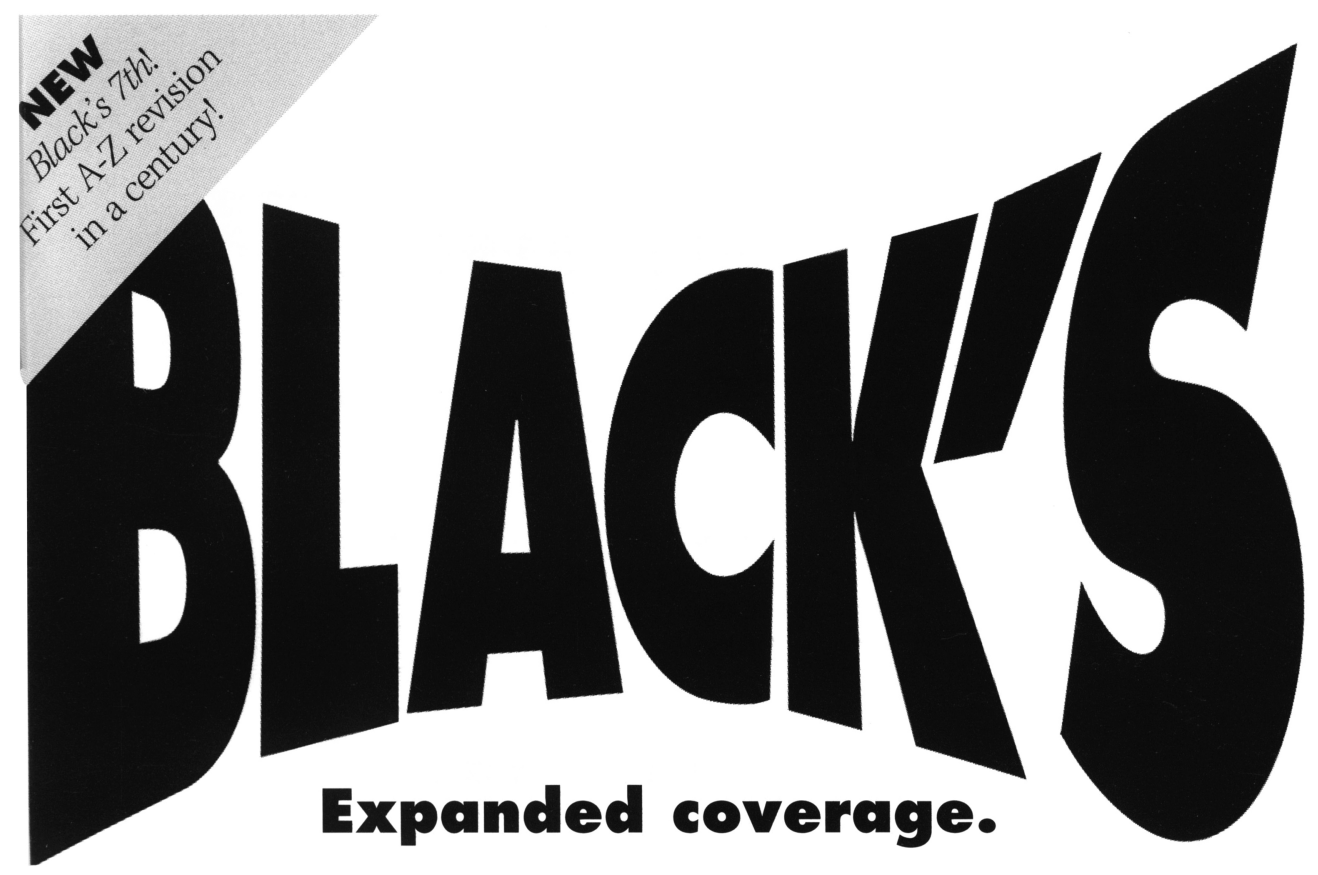

The publication of a new Black's Law Dictionary ${ }^{\odot}$ is a historic event. More than 4,500 terms - from "Megan's Law" to "cybersquatting" - are covered together for the first time in any legal dictionary. It is by far the most thorough revision of this classic legal reference in over 100 years.

Black's 7th includes expanded international coverage including more citations and terms related to public international law, International Court of Justice, and the World Court.

\section{Better clarity.}

Plus, more than 30,000 entries have been totally reviewed and improved by the world's leading legal lexicographer, Bryan Garner. Every definition is clearer, more precise and easier to comprehend.

\section{4,500 new definitions. 30,000 revised definitions.}

The world's leading legal dictionary, now better than ever. See for yourself. IALL members, call 1-651-687-7921 for your special Black's discount.

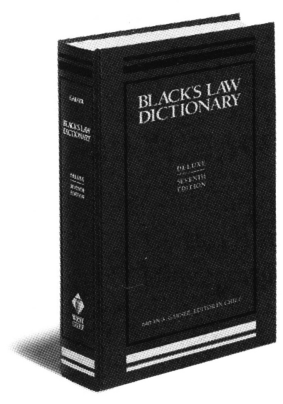




\section{INTERNATIONAL JOURNAL}

OF LEGAL INFORMATION

Presorted

P.O. Box 5709

Washington, D.C. 20016-1309

U.S.A.

(202) 707-9866

Fax: (202) 707-1820

E-mail: mber@loc.gov 